\title{
A CASE OF T-CELL PSEUDOLYMHOMA RESULTING FROM TREATMENT WITH D- PENICILAMIN - CASE REPORT
}

\author{
Shtilionova S. ${ }^{1}$ P. Drumeva ${ }^{1}$, M. Balabanova ${ }^{3}$, I. Krasnaliev ${ }^{2}$ \\ ${ }^{1}$ Department of dermatology and venereology - Medical University - Varna \\ ${ }^{2}$ Department of pathology - Medical University - Varna \\ ${ }^{3}$ Department of dermatology and venereology - Medical University - Sofia
}

Reviewed by: prof. A. Klisarova

\section{SUMMARY}

D-penicilamin is a medicine that is well resorbed by gastro - intestinal tract. It is metabolized by the liver. It has the ability to connect in hilate complexes the ions of the heavy metals. D-penicilamine is a therapeutic agent in hepato-lenficular degeneration - performed by lack of ceruloplasmin resulting in cumulation of copper in the liver and in leuticular substance of the brain $(1,3)$.

Key words: Cutis pseudolyphomas /CP/, D-penicilamin

We present a patient - 69 years old male who was treated with D - penicilamine - 3 times daily ( $3 \mathrm{~g})$ for 6 months because of Wilson - Conoralov disease (2).

At the end of the third month the patient formed nodular redish eruption localized in retrocuricul and sub maudibular areas.

The skin biopsy showed the pattern of T-cell pseudolymhoma.

The skin pseudolymphomas are a heterogeneous group benign reactive lymphoproliferative processes with different etiology, simulating clinical or histological malignant skin lymphomas.

Depending on the type of cellular infiltrate the skin pseudolymphomas are divided into T-cellular and in B-cellular. There is a wide spectrum of etiologic factors that may provoke the appearance of skin pseudolymphomas.

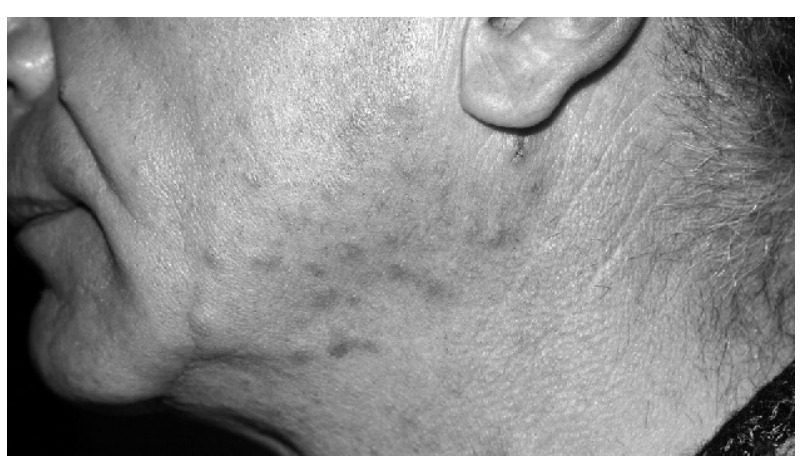

Fig. 1

Address for correspondence:

S. Shtilionova, Dept. of dermatology and venereology - Medical

University - Varna

e-mail: shtilionova@abv.bg
Large is the group of medicines, which locally or systematically applicated can induce the development of skin pseudolymphomas, such as anticonvulsants, neuroleptics, tranquilizers, ACE - inhibitors, antirheumatic means (4). These medicament caused skin pseudolymphomas occure from one month to one year after the beginning of therapy. There are localized papules, single or multiplexing nodules and plates, generalized palpulonodular lesions and exfoliative erythroderma resembling syndrome of Sezary. $\mathrm{D}$-penicillamin (Cuprinil) is of the group of antirheumathic drugs and often is a choice in the therapy of Willson Konovalov disease . It is resorbed in gastro-intestinal tract and metabolized in the liver. It has the ability to connect copper ions in chelate complexes.

We present a 69 year old patient, treated with D-penicillamin 3 times a day with $3 \mathrm{~g}$ for a period of 6 months on the occasion of Willson - Konovalov disease. In the course of the treatment after the 3 /third/ month behind the ears and below the lower jaw appear single and later multiple small roundish consistencies with slight peeling on the surface.

The patient developed febrility, lymphadenopathy, hepatosplenomegaly, blood eosinophilia.

\section{From dermatologic status:}

Retroauricular and submandibular are erythemic scattered meadow papules, compact plates size $4-5 \mathrm{~cm}$. Fine desquamation. After skin biopsy, the histopathological research found surface and deep infiltrate composed mainly of lymphocytes, lymphoid cells with significant availability of plasmocytes and histocytes and less eosinophils and mastocytes. Presence of epithelial granulomas, giant cells, and tangible bodies. 
The patient was monitored for the dynamics of skin lesions and the paraclinical deviations 1 /one/ month after the completion of treatment with D-penicillamin.

It was found reverse development of the clinical symptoms and normalization of paraclinical indicators.

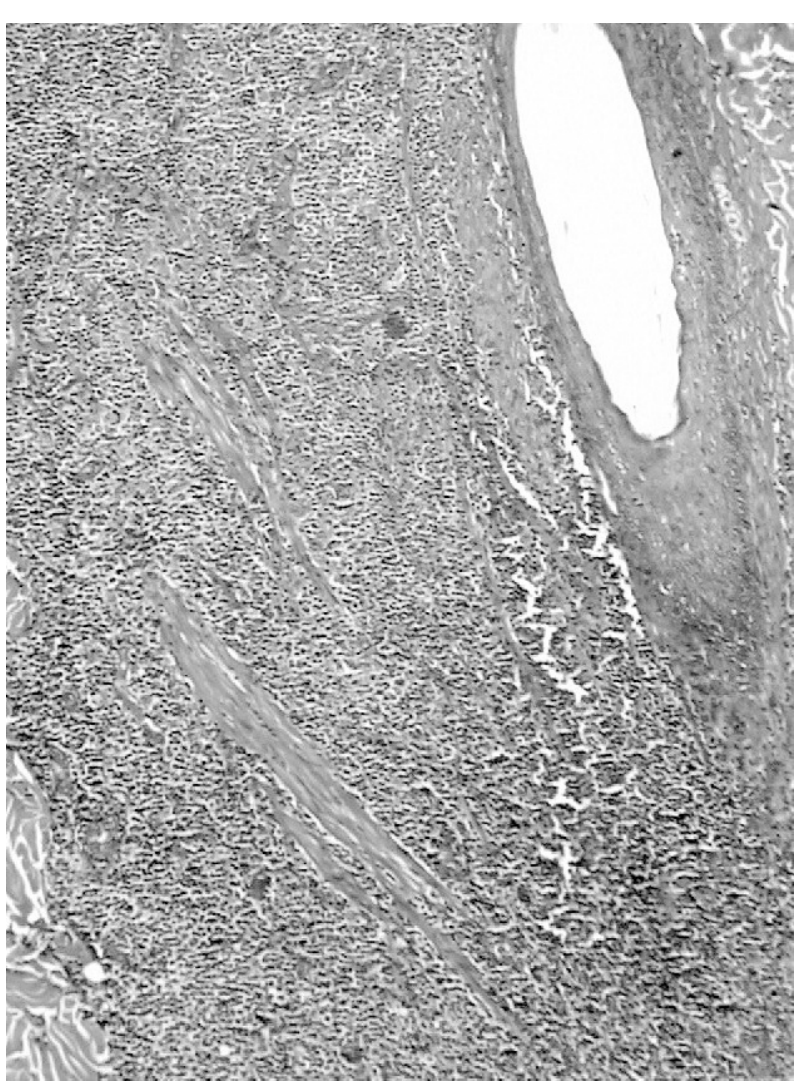

Fig. 2

\section{DISCUSSION}

In skin pseudolymphomas caused by drugs, clinical and immunological changes disappear from 3/three/ to 4 /four/ weeks after stopping the medicinal means D - penicillamin. In skin pseudolymphomas caused by medications there is reduced immunological function and disrupted immune control, which leads to abnormal proliferation of lymphocytes, increased function of T-suppressors and hypogammaglobulinemia.

In cases when histology shows malignant changes and the disease does not fade away after stopping the medications, it is recommended continuous control monitoring of patients with skin pseudolymphomas, in respect of their possible malignancy.

\section{BIBLIOGRAPHY}

1. Braddock SW, Harrongton D, Vose J. Generalized nodular cutaneous pseudolymphoma associated with phenytion therapy. J Am Acad Dermatol 1992.

2. Brown MD, Ellis CN, Billings J, et al. Rapid occurrence of nodular cutaneous T-lymphocyte infiltrates with cyclosporine therapy. Arch Dermatol 1988.

3. Crowson AN, Margo CM. Antidepressant therapy: a possible cause of atypical lymphoid hyperplasia. Arch Dermatol 1995.

4. D'Incan M, Souteyrand P, Bignon YJ, et al. Hydantoin induced cutaneous pseudolymphoma with clinical, pathologic, and immunologic aspects of Sézary syndrome. Arch Dermatol 1992.

5. Dorfman RF, Warnke R. Lymphadenopathy simulating the malignant lymphomas. Hum Pathol 1974. 